\title{
Hypercalcemia of Malignancy and Colorectal Cancer
}

\author{
Rodolfo J. Galindo, ${ }^{\mathrm{a}, \mathrm{c}}$, Isabela Romao ${ }^{\mathrm{b}}$, Ageliki Valsamis ${ }^{\mathrm{b}}$, Stuart Weinerman ${ }^{\mathrm{b}}$, \\ Yael Tobi Harris ${ }^{b}$
}

\begin{abstract}
Our aim is to describe the association between colorectal cancer (CRC) and humoral hypercalcemia of malignancy (HHM). Causes of hypercalcemia of malignancy include parathyroid hormone-related peptide (PTHrP) secretion, local osteolysis, calcitriol production and ectopic parathyroid hormone (PTH) secretion. Hypercalcemia of malignancy in patients with CRCs is a rare scenario. A patient with anal squamous cell carcinoma was admitted with hypercalcemia, suppressed PTH and hypophosphatemia. He was found to have metastatic anal squamous cell carcinoma to the liver. Further evaluation revealed elevated PTHrP and 1,25-dihydroxyvitamin D and low 25-hydroxyvitamin D. Over a 5-month course, the hypercalcemia responded poorly to bisphosphonates, transiently to prednisone, but showed marked improvement with chemotherapy. A review of English language publications in Pubmed and a reference search of retrieved articles revealed 29 cases of CRC causing PTHrP-mediated hypercalcemia. Most patients were middle-aged men (mean \pm SD: $56.7 \pm 13.4$ years), with advanced metastatic cancer ( $85 \%$ with hepatic metastasis) and severe hypercalcemia (mean \pm SD: $15.6 \pm 1.9 \mathrm{mg} / \mathrm{dL}, 62 \%$ with $\mathrm{Ca}>$ 14). This condition is associated with high mortality (79\%) and short survival (median 54.5 days, CI: 21 - 168). Despite being uncommon, HHM (PTHrP-mediated) should be considered in patients with metastatic CRC presenting with hypercalcemia. Clinicians should be aware that combined etiologies may be present, particularly in cases of resistant hypercalcemia. Treatment of the underlying malignancy is essential for calcium control.
\end{abstract}

Keywords: Hypercalcemia; Parathyroid hormone-related peptide; Calcitriol; Colorectal cancer; Combined mechanism of hypercalcemia

Manuscript accepted for publication January 27, 2016

acahn School of Medicine at Mount Sinai, Division of Endocrinology, Diabetes and Bone Diseases, Mount Sinai St. Luke's Hospital, 1111 Amsterdam Ave, Babcock Building 10th Floor, Room 1020, New York, NY 10025, USA ${ }^{b}$ Hofstra North-Shore LIJ School of Medicine, Division of Endocrinology Diabetes and Metabolism, 865 Northern Boulevard, Suite 203, Great Neck, NY 11021, USA

${ }^{\mathrm{c} C}$ Corresponding Author: Rodolfo J. Galindo, Icahn School of Medicine at Mount Sinai, Division of Endocrinology, Diabetes and Bone Diseases, Mount Sinai St Luke Hospital, 1111 Amsterdam Ave, Babcock Building 10th Floor, Room 1020, New York, NY 10025, USA. Email: rgalindo@chpnet.org

doi: http://dx.doi.org/10.14740/wjon953w

\section{Introduction}

Malignancy is the most common cause of hypercalcemia in hospitalized patients [1]. The differential diagnosis of malignancy-associated hypercalcemia includes, in decreasing order of frequency $[2,3]$, humoral hypercalcemia of malignancy (HHM) secondary to secretion of parathyroid hormonerelated peptide (PTHrP), generally by squamous cell tumors $[4,5]$; local osteolytic hypercalcemia, caused by cytokines, chemokines and PTHrP $[5,6]$; calcitriol-mediated hypercalcemia, seen most commonly in lymphomas and leukemias [5,7]; and rarely ectopic hyperparathyroidism [5, 8]. These mechanisms are not mutually exclusive and combined causes are rare but should also be considered.

HHM is frequently seen in squamous cell cancers of the head and neck, esophagus, cervix and lung [3], as well as breast cancer [4], renal cell carcinoma [9] and hematological malignancies [5]. Additionally, Asa et al reported elevated expression of PTHrP in pheochromocytomas, thyroid carcinomas and small cell lung carcinomas [10].

Here we present a rare case of colorectal cancer (CRC) and hypercalcemia of malignancy with elevation of PTHrP and calcitriol. We also provide a literature review of HHM in CRC. To our knowledge, this is the first reported case of calcitriolinduced hypercalcemia in human CRC.

\section{Case Report}

A 58-year-old man presented with syncope and falls during postural changes. He had been diagnosed with anal squamous cell carcinoma 1 year prior, and had responded well to chemotherapy. No systemic disease had been found on initial staging. He also had a history of bipolar disorder but was never treated with lithium. His medications included gabapentin and docusate. On presentation, he was bradycardic to $48 \mathrm{bpm}$ and had orthostatic hypotension. Physical exam revealed temporal wasting, dry mucous membranes, leg edema and mild confusion. Laboratory evaluation showed hypercalcemia (corrected calcium of $15.3 \mathrm{mg} / \mathrm{dL}$, reference range $8.4-10.5 \mathrm{mg} / \mathrm{dL}$ ), suppressed parathyroid hormone (PTH) of $8.5 \mathrm{pg} / \mathrm{mL}$ (15$65 \mathrm{pg} / \mathrm{mL})$ and hypophosphatemia $\left(\mathrm{PO}_{4}\right.$ of $1.9 \mathrm{mg} / \mathrm{dL}$, reference range $2.5-4.5 \mathrm{mg} / \mathrm{dL}$ ). CT scans of the head and chest were unremarkable. Bone scan did not reveal any lesions. CT 


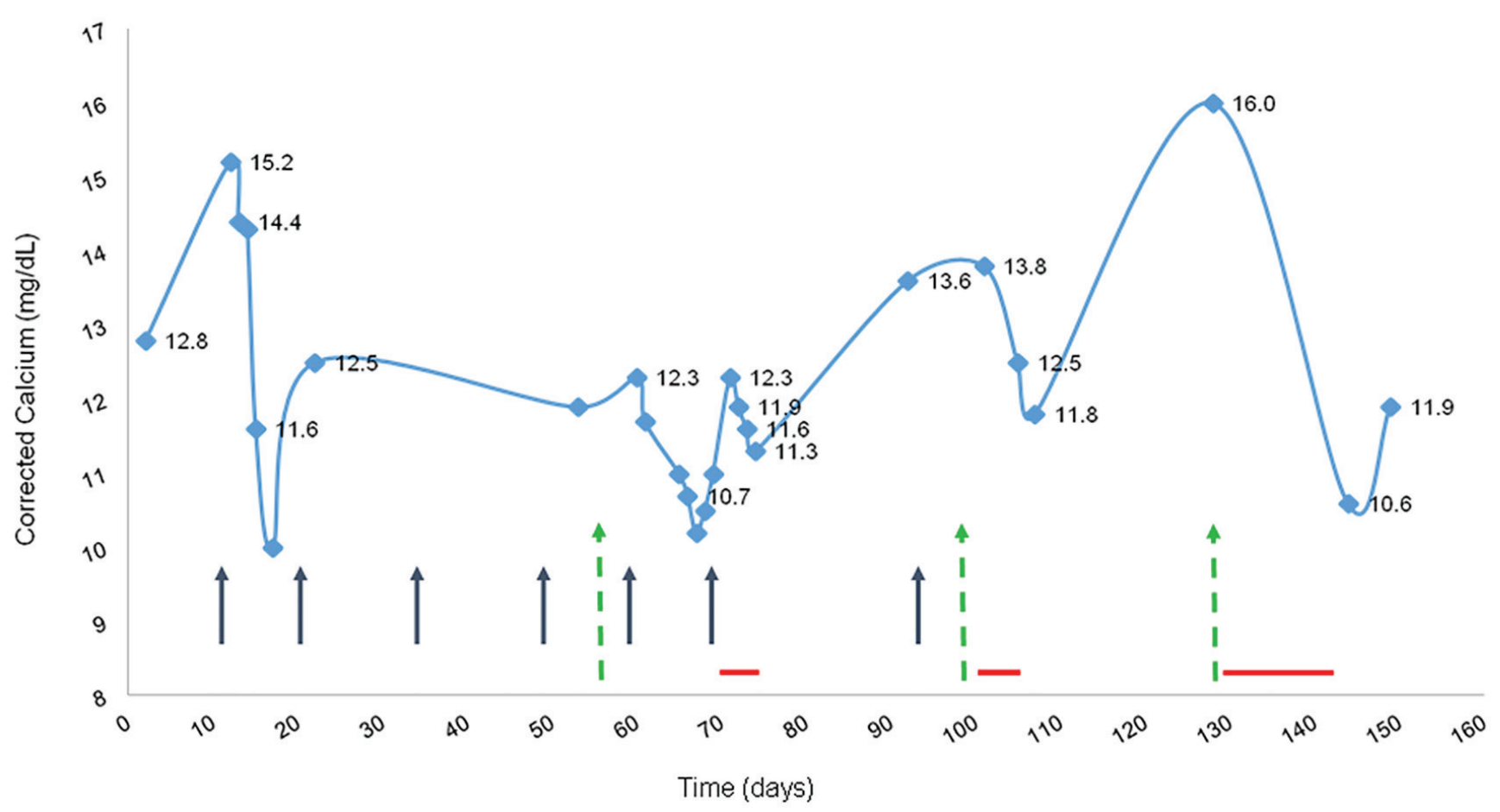

Figure 1. Corrected calcium and response to therapy. Black arrows represent treatment with zoledronic acid; green dashedarrows represent chemotherapy and dexamethasone; red horizontal lines represent prednisone treatment (40 mg daily).

scan of the abdomen and pelvis demonstrated multiple solid hepatic lesions. A liver biopsy revealed metastatic squamous cell carcinoma. Further evaluation for hypercalcemia revealed elevated PTHrP $(6.7 \mathrm{pmol} / \mathrm{L}$, reference range $<2 \mathrm{pmol} / \mathrm{L})$, decreased 25-hydroxyvitamin D $(25(\mathrm{OH}) \mathrm{D}$ of $27.2 \mathrm{ng} / \mathrm{ml}$, reference range $30-100 \mathrm{ng} / \mathrm{mL})$ and increased calcitriol $(75 \mathrm{pg} /$ $\mathrm{mL}$, reference range $18-64 \mathrm{pg} / \mathrm{mL}$ ). A diagnostic evaluation for causes of elevated calcitriol was unrevealing. Fibroblastgrowth-factor 23 and angiotensin-converting enzyme levels were within normal limits. Blood, urine and spinal fluid cultures revealed no growth of any organism, and extensive virology testing showed only active hepatitis $\mathrm{C}$ virus infection. Imaging studies did not identify granulomatous disease. The patient's calcium level improved transiently with standard therapy with saline hydration, calcitonin and zoledronic acid, and he was discharged home. A few weeks later, the patient was again admitted and had elevated $\mathrm{CCa}, \mathrm{PTHrP}$ and calcitriol (12.3 mg/dL, $11 \mathrm{pmol} / \mathrm{L}$ and $205 \mathrm{pg} / \mathrm{mL}$, respectively), which no longer responded to zoledronic acid, despite several courses of therapy. He received chemotherapy - cisplatin, 5-fluorouracil, and dexamethasone - and his CCa levels transiently improved. After rapid recurrence of hypercalcemia, prednisone $40 \mathrm{mg}$ daily was started and calcium levels began to decrease. The patient stopped taking his prednisone due to concern about elevated blood glucose and his calcium immediately increased again. Over a period of 5 months, the hypercalcemia responded weakly to bisphosphonates and transiently to prednisone but recurred immediately after cessation of therapy, as shown in Figure 1. Only chemotherapy achieved a significant improvement in calcium levels.

\section{Discussion}

\section{Literature review}

A Pubmed search of English language articles with multiple combinations of the terms including hypercalcemia, colorectal/ anal cancer, metastasis, hypercalcemia of malignancy, PTHrP, calcitriol and combined causes, was performed. Related citations and cited references from retrieved articles were also reviewed. Fisher's exact tests were performed to assess the relationship between calcium level and attributable death and between PTHrP level and attributable death. A survival distribution was estimated using the Kaplan-Meier product-limit method, whereby a survival time was considered "censored" at the time of last follow-up if the patient was alive or lost to follow-up. Comparisons of time-to-death for subjects with varying levels of calcium and PTHrP were each carried out using the log-rank test.

Our search revealed 29 cases of CRC with hypercalcemia due to PTHrP secretion (Table 1) [11-36], of which only five were anal squamous carcinoma $[17,24,30,32,34]$. Of the remaining cases, 18 described carcinoma of the colon and six of the rectum. The mean patient age was 56.7 years (mean \pm SD: $56.7 \pm 13.4$ years), and $55 \%$ were male (in two cases, gender was not reported). Twenty-one cases involved metastatic disease, of which $85 \%$ had hepatic involvement. Total calcium 
Table 1. Cases of Colorectal Cancer and Humoral Hypercalcemia of Malignancy

\begin{tabular}{llllllll}
\hline Case number & Year (reference) & Age & Sex & Histological diagnosis & Metastasis & Calcium (mg/dL) & PTHrP (pmol/L) \\
\hline 1 & $1963[35]$ & 77 & M & Cac & Li, LN & 14 & NR \\
2 & $1969[36]$ & 46 & M & Cac & Li & 15 & NR \\
3 & $1969[25]$ & 79 & M & Cc & NR & 17.8 & NR \\
4 & $1980[18]$ & 43 & M & Cas & Li, P, K & 18.4 & NR \\
5 & $1980[18]$ & 39 & M & Ras & Li, A & 15.8 & NR \\
6 & $1985[26]$ & 67 & F & Ras* & Li, P, T, B, Per, Ad & 16 & NR \\
7 & $1987[23]$ & 41 & F & Cas & Li & NR & NR \\
8 & $1987[12]$ & 41 & F & Cas & Li, LN & 18.4 & NR \\
9 & $1989[11]$ & 74 & M & Cas & Li, P & 14.5 & NR \\
10 & $1991[22]$ & 58 & M & Rac & Li & 17.6 & NR
\end{tabular}

Cases reported after commercial assays became available

\begin{tabular}{|c|c|c|c|c|c|c|c|}
\hline 11 & 1993 [16] & NR & NR & $\mathrm{Cc}$ & NR & NR & 10 \\
\hline 12 & 1993 [16] & NR & NR & $\mathrm{Cc}$ & NR & NR & 20 \\
\hline 13 & 1994 [19] & 58 & M & Cas & $\mathrm{Li}$ & 11.9 & 25 \\
\hline 14 & $1995[14]$ & 52 & $\mathrm{~F}$ & $\mathrm{Rac}$ & $\mathrm{Li}$ & 18 & 162 \\
\hline 15 & 1995 [24] & 60 & M & Ac & $\mathrm{Pr}, \mathrm{LN}$ & 17.3 & 33.2 \\
\hline 16 & $1996[31]$ & 75 & M & $\mathrm{Cac}^{*}$ & $\mathrm{Li}, \mathrm{LN}$ & 13.2 & 36.7 \\
\hline 17 & 1996 [27] & 37 & $\mathrm{~F}$ & Cas & $\mathrm{Li}, \mathrm{LN}$ & NR & NR \\
\hline 18 & 1998 [29] & 47 & M & $\mathrm{Cc}$ & NR & 16 & NR \\
\hline 19 & 1999 [20] & 54 & F & $\mathrm{Cac}^{*}$ & $\mathrm{Li}, \mathrm{LN}$ & 15.2 & 18 \\
\hline 20 & 1999 [20] & 63 & M & Rac & Li, P, LN, S & 17 & 9.3 \\
\hline 21 & 2001 [33] & 76 & $\mathrm{~F}$ & Cas & $\mathrm{Li}, \mathrm{LN}, \mathrm{S}$ & 13.6 & 25.7 \\
\hline 22 & 2002 [21] & 42 & M & $\mathrm{Cac}^{*}$ & Li, LN, B, S & 16.2 & 12.1 \\
\hline 23 & 2005 [15] & 78 & F & Cas & No & 13.2 & 3.7 \\
\hline 24 & 2005 [28] & 54 & $\mathrm{~F}$ & $\mathrm{Cac}$ & Li, LN, P & 14.2 & 13.5 \\
\hline 25 & 2006 [13] & 59 & $\mathrm{~F}$ & $\mathrm{Rc}^{*}$ & $\mathrm{LN}$ & 12.7 & 6.4 \\
\hline 26 & 2008 [32] & 57 & M & Ascc & No & 14 & NR \\
\hline 27 & 2009 [17] & 40 & $\mathrm{~F}$ & Ascc & No & 15.8 & $\mathrm{HIGH}$ \\
\hline 28 & 2010 [30] & 52 & $\mathrm{~F}$ & Ascc & No & 17.2 & NR \\
\hline 29 & $2011[34]$ & 64 & M & Ascc & $\mathrm{LN}$ & 17.6 & 3.4 \\
\hline
\end{tabular}

Ca: highest calcium (mg/dL); PTHrP: highest parathyroid hormone-related peptide (pmol/L). Histology: Cac: colon adenocarcinoma; Cas: colon adenosquamous carcinoma; Rc: rectal carcinoma; Rac: rectal adenocarcinoma; Ras: rectal adenosquamous; Cc: colon cancer unspecified; Ac: anal carcinoma; Ascc: anal squamous cell carcinoma. *Neuroendocrine features. Metastasis: Li: liver; LN: lymph node; P: pulmonary; Per: peritoneum; Ad: adrenal; B: bone; T: thyroid; NR: no reported; No: no metastasis; S: skin; Pr: prostate.

levels ranged from 11.9 to $18.4 \mathrm{mg} / \mathrm{dL}$ (mean $\pm \mathrm{SD}: 15.6 \pm 1.9$ $\mathrm{mg} / \mathrm{dL})$. Most patients (62\%) presented with severe hypercalcemia $(\mathrm{Ca}>14 \mathrm{mg} / \mathrm{dL})$. Cases published prior to 1993 refer to a PTH-like substance, and the term PTHrP as a defined protein appears thereafter, as clinically useful assays to measure PTHrP became available [4]. PTHrP levels were reported in 14 cases, and ranged from 3.4 to $162 \mathrm{pmol} / \mathrm{L}$ (mean \pm SD: 27.07 $\pm 40.2 \mathrm{pmol} / \mathrm{L})$. The median overall time-to-attributable death was 54.5 days (95\% CI: 21 - 168). Neither the relationship between calcium and death nor PTHrP and death was found to be statistically significant ( $\mathrm{P}=0.1142$ and $\mathrm{P}=1.0$, respectively). Based on the log-rank test, there was no significant difference between those who had calcium level $<12,12-14$ or $>14$ with respect to the time-to-attributable death $(\mathrm{P}<0.2899)$. There was also no significant association between calcium level and PTHrP $(\mathrm{P}=0.76)$.

Our search did not reveal any case of calcitriol-induced hypercalcemia in patients with $\mathrm{CRC}$, making this the first reported case. Moreover, we found only five cases of hypercalcemia from combined production of calcitriol and PTHrP: three ovarian adenocarcinomas, one renal cell carcinoma, and one pancreatic cancer with neuroendocrine features (Table 2) [3741]. In this group, patients had moderate to severe hypercalcemia $(12.9$ - $18.9 \mathrm{mg} / \mathrm{dL})$ on presentation. PTHrP ranged from 
Table 2. Cases of Combined Paraneoplastic Production of Parathyroid Hormone-Related Peptide (PTHrP) and Calcitriol

\begin{tabular}{|c|c|c|c|c|c|c|c|c|}
\hline $\begin{array}{l}\text { Case } \\
\text { number }\end{array}$ & $\begin{array}{l}\text { Year } \\
\text { (reference) }\end{array}$ & Age & Sex & $\begin{array}{l}\text { Histological } \\
\text { diagnosis }\end{array}$ & Metastasis & $\begin{array}{l}\text { Calcium } \\
(8.4-10.5 \mathrm{mg} / \mathrm{dL})\end{array}$ & $\begin{array}{l}\text { PTHrP } \\
(<2 \mathrm{pmol} / \mathrm{L})\end{array}$ & $\begin{array}{l}\text { Calcitriol } \\
(18-64 \mathrm{pg} / \mathrm{mL})\end{array}$ \\
\hline 1 & 1991 [39] & 70 & $\mathrm{~F}$ & Oac & No & 13.08 & NR & 285 \\
\hline 2 & 2000 [38] & 54 & $\mathrm{~F}$ & Oac & No & 16.8 & 10 & 104 \\
\hline 3 & 2006 [37] & 74 & $\mathrm{~F}$ & Oac & No & 12.8 & 60.4 & 116 \\
\hline 4 & 2007 [41] & 59 & M & PNE & No & 18.9 & 7.3 & 71.5 \\
\hline 5 & 2009 [40] & 57 & M & $\mathrm{RCC}$ & $\mathrm{Li}$ & 12.9 & 3.4 & 79 \\
\hline
\end{tabular}

RCC: renal cell carcinoma; Oac: ovarian adenocarcinoma; PNE: pancreatic neuroendocrine tumor; Ascc: anal squamous cell carcinoma. Metastasis: Li: liver. Calcium, PTHrP and calcitriol: highest reported values.

3.4 to $60.4 \mathrm{pmol} / \mathrm{L}$ and calcitriol ranged from 71.5 to $285 \mathrm{mg} /$ dL. Notably, in four of the five cases, the patients survived the hypercalcemic episode [37-39, 41].

\section{Characteristics of HHM and CRC}

We report a case of combined PTHrP and calcitriol-induced hypercalcemia from CRC, adding to the literature of patients with CRC with HHM. As was the case for our patient, HHM in CRC typically occurs in middle-aged patients with advanced metastatic disease, usually to the liver. This condition is associated with severe hypercalcemia (62\%), high mortality (79.1\%), and short survival (median: 54.5 days). We did not find a statistically significant relationship between the reported calcium levels and length of survival. However, calcium levels reported in these cases represent only one point in time and do not reflect response to treatment, overall burden of disease, or other factors that affect survival. In the cases with reported PTHrP values, we found no significant association between PTHrP and calcium. One explanation for these findings may be that the assay for PTHrP was newly discovered and may not have been standardized between laboratories. Additionally, as this study had a very small sample size, there may have not been sufficient power to detect a small, yet clinically meaningful, difference in survival among groups.

\section{Paraneoplastic PTHrP production and CRC}

This patient with metastatic $\mathrm{CRC}$ and recurrent hypercalcemia had a unique etiological mechanism: combined paraneoplastic production of PTHrP and calcitriol. PTHrP is a hormone functionally and structurally related to PTH. In 1941, Albright was the first to suggest that a hypernephroma was secreting a PTHlike substance [35]. It was not until the 1980s - 1990s that it was biochemically characterized and named PTHrP by a series of studies [42]. PTHrP selectively binds and activates the PTH receptor-1 and produces similar effects to those of PTH. It causes hypercalcemia by increasing osteoclastic resorptive activity and renal calcium reabsorption and causes hypophosphatemia by decreasing phosphorus reabsorption [2, 42, 43]. PTHrP differs from PTH, however, in that it decreases osteoblastic activity leading to unrestricted bone resorption $[43,44]$ and it is associated with lower calcitriol levels due to weaker stimulation of 1-alpha hydroxylase [45]. PTHrP is frequently produced by squamous cell cancers of the head and neck, esophagus, cervix and lung [3], as well as breast cancer [4], renal cell carcinoma [9] and hematological malignancies [5]. Additionally, Asa et al reported elevated expression of PTHrP in pheochromocytomas, thyroid carcinomas and small cell lung carcinomas [10]. Our review revealed 29 additional cases from CRCs.

\section{Management of PTHrP-mediated hypercalcemia (HHM)}

Management includes general treatment of hypercalcemia along with specific therapies to target the pathophysiological mechanism. Hypercalcemia induces free water diuresis that may lead to volume depletion. Moreover, patients with malignancies may have decreased oral intake further worsening their nutritional and volume status. Thus, saline hydration is imperative for most patients. Calciuresis with loop diuretics is only recommended in those cases with volume overload or after adequate volume repletion is achieved.

Agents that block PTHrP-mediated increased bone resorption, such as pamidronate and zoledronic acid, will target the underlying disorder. Zoledronic acid is considered first-line, as it is highly effective in patients with HHM, benefiting more patients, and leading to a more rapid decrease in calcium than pamidronate $[46,47]$. Calcitonin may transiently lower calcium for 24 - 48 h. Denosumab, a human monoclonal antibody that inhibits the receptor activator of nuclear factor kappa-b ligand, was recently shown to decrease serum calcium in $64 \%$ of patients with HHM despite recent intravenous bisphosphonate treatment [48]. Vitamin D deficiency, very common in cancer patients [49], may predispose them to severe and prolonged hypocalcemia from anti-resorptive therapy, thus those with subclinical osteomalacia should start vitamin D supplementation [50]. Our patient initially responded to zoledronic acid, but subsequently became refractory to therapy despite having a PTHrP level thought to be optimally responsive to bisphosphonates [16].

\section{Calcitriol-mediated hypercalcemia}

The minimal response to bisphosphonate therapy may have been due to the presence of a second mechanism of hypercalcemia: calcitriol-mediated hypercalcemia. Our patient had 


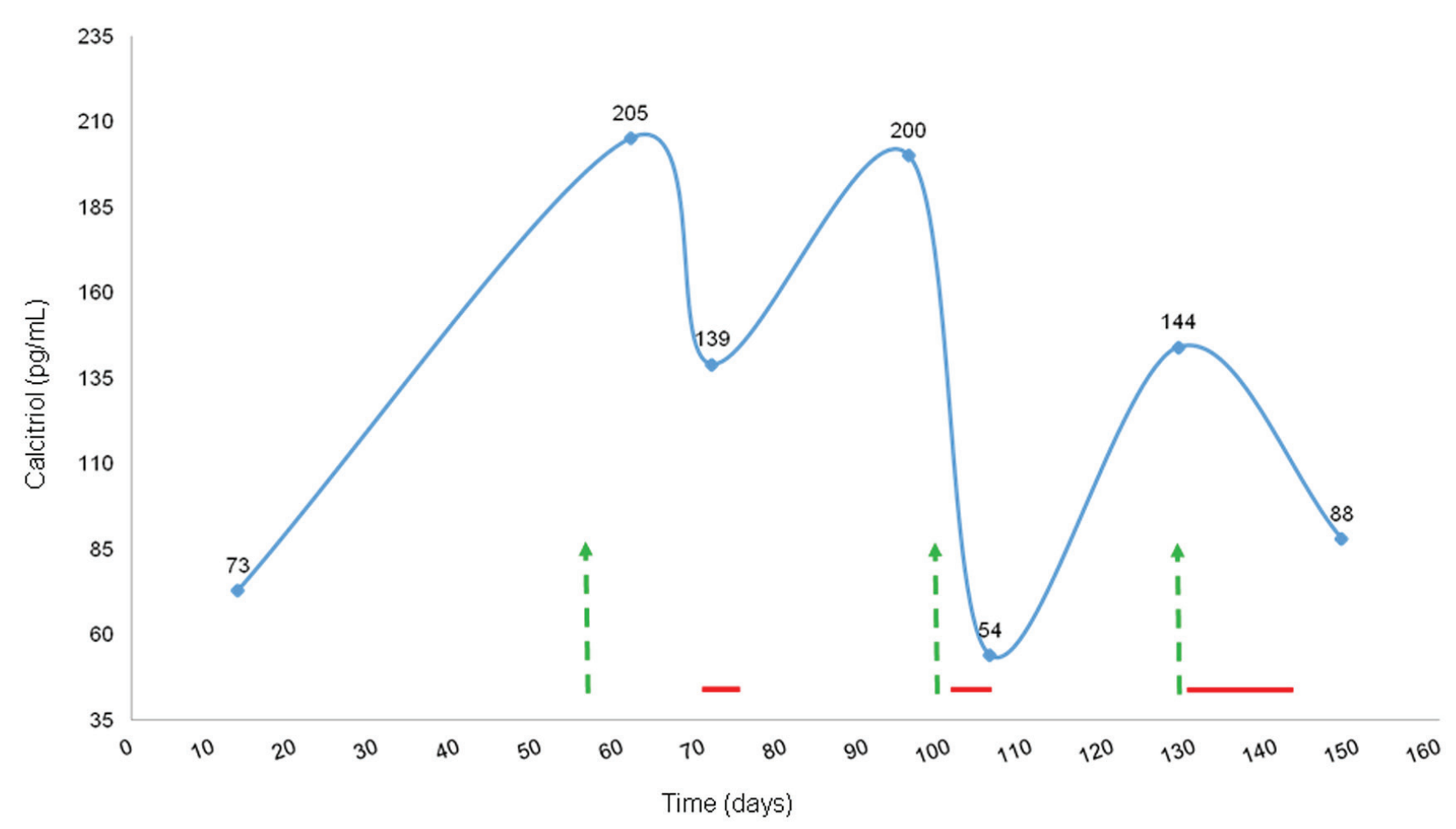

Figure 2. Calcitriol levels and response to steroids and chemotherapy. Green arrows represent chemotherapy and dexamethasone; red horizontal lines represent prednisone treatment (40 mg daily).

markedly elevated calcitriol levels on several measurements, as shown in Figure 2, with no other identifiable cause. Calcitriol (1,25-dihydroxyvitamin D), the active form of vitamin D, is converted from $25(\mathrm{OH}) \mathrm{D}$ by the renal 1-alpha hydroxylase, which is stimulated by PTH, and causes hypercalcemia by increasing intestinal calcium absorption. The 25-hydroxyvitamin D3 1-alpha-hydroxylase, encoded by the CYP27B1 gene, is also found outside of the kidney in cells including macrophages [51], but its normal role in these tissues is unclear [52]. Extra-renal over-expression of this gene is responsible for the paraneoplastic production of calcitriol seen in lymphomas and leukemias [53, 54]. Recently, a large retrospective series of 101 patients with calcitriol-mediated hypercalcemia by Donovan et al reported that sarcoidosis was the most common cause $(49 \%)$, followed by hematological malignancies $(17 \%)$ and granulomatous infections (8\%). Solid tumors comprised only $5 \%$ of cases and included ovarian cystadenocarcinoma, seminoma, and metastatic squamous cell carcinoma of the tongue and non-small cell carcinoma of the lung. The median calcitriol level in patients with malignancy was 184 $\mathrm{pmol} / \mathrm{L}$ (interquartile range 140 - $230 \mathrm{pmol} / \mathrm{L}$ ) [7]. A review of rare causes of calcitriol-mediated hypercalcemia also reported dysgerminomas, leiomyoblastoma and squamous cell bronchogenic carcinoma [55]. Additionally, expression of 1-alpha hydroxylase has been demonstrated in malignant and normal colon cells, with higher mRNA expression in the less-differentiated tumors, compared to normal peri-tumoral cells [56], although hypercalcemia has not been reported.

Since the discovery of fibroblast growth factor-23 (FGF23), new insights in the metabolism of phosphorus and 1,25-dihydroxyvitamin D have been proposed. FGF-23 is a bone-derived hormone that inhibits phosphorus reabsorption, resulting in hypophosphatemia. FGF-23 also inhibits 1-alpha hydroxylase and stimulates 24-hydroxylase resulting in decreased levels of calcitriol [57]. Our patient had low phosphorus levels, but the fact that the FGF-23 levels were within normal limits excluded any mechanistic implications.

\section{Management of calcitriol-induced hypercalcemia}

As above, general measures, such as saline hydration, are indicated. Additionally, limiting sun exposure and calcium intake will target the underlying mechanism of hypercalcemia. Further treatment involves glucocorticoids, which inhibit extra-renal 1-alpha hydroxylase [54, 58-60], leading to a rapid decrease in calcitriol followed by a later decrease in serum and urinary calcium [61]. The anti-inflammatory/cytotoxic properties of glucocorticoids, leading to less 1-alpha hydroxylase activity, have been proposed as an additional mechanism; however, this effect was not seen in patients with lymphoma [54] and sarcoidosis-related hypercalcemia [61]. Typical prednisone doses range from 10 to $40 \mathrm{mg}$ per day but cancer patients may require higher doses $[54,61]$. 


\section{Combined production of PTHrP and calcitriol}

Combined secretion of PTHrP and calcitriol by tumors is extremely rare and has only been reported in five cases: one renal cell carcinoma [40], another in a pancreatic neuroendocrine tumor [41], and three in ovarian cancers [37-39] (Table 2). We report the sixth case of combined production of PTHrP and calcitriol. In three of the previously reported cases, the hypercalcemia did not respond to bisphosphonates [39-41]. Steroids improved calcium levels in one patient who failed to respond to two doses of pamidronate. Hypercalcemia improved in two cases after surgery $[37,39]$. In a third case, calcium normalized after the second surgery, and had transiently responded to bisphosphonates [38]. Ultimately, chemotherapy induced resolution of the hypercalcemia in most cases, emphasizing the importance of targeted therapy against the tumor.

Our patient had elevated levels of both PTHrP and calcitriol. We were unable to confirm elevated 1-alpha hydroxylase activity in the liver metastases and surrounding cells due to lack of tissue. It is therefore possible that the elevated calcitriol levels were due to stimulation of renal 1-alpha hydroxylase by the PTHrP, rather than extra-renal overproduction of 1-alpha hydroxylase, while PTH remained suppressed during the disease course. The effect of PTHrP on renal 1-alpha hydroxylase is somewhat controversial. PTHrP has been shown to cause lower levels of renal conversion of $25(\mathrm{OH}) \mathrm{D}$ to calcitriol than does PTH [43], and Schilling et al demonstrated that PTHrP does not influence calcitriol levels in patients with HHM [62]. Horwitz and colleagues used high doses of PTHrP [1-36] and PTH [1-34] infusions to demonstrate that PTHrP does have a stimulatory effect on renal calcitriol production, but much weaker than that of PTH [45, 63]. More recently, this same group demonstrated that PTHrP, at the lowest required dose to induce hypercalcemia, produced a decrease of calcitriol levels in healthy volunteers [64]. Thus, PTHrP seems not to increase calcitriol to levels similar to that of PTH. Given the weak effect of PTHrP, it is unlikely that the high levels of 1,25-dihydroxyvitamin D seen in our patient were due to its effects.

In our patient, bisphosphonate therapy did not consistently decrease calcium, while prednisone treatment significantly reduced calcitriol and decreased the calcium level. This finding was also reported by Shivnani et al, the only case of combined etiology with confirmed tumoral expression of 1-alpha hydroxylase [40]. Moreover, both calcitriol and calcium levels rose rapidly after the discontinuation of prednisone. The response to glucocorticoids as well as this patient's markedly elevated calcitriol levels (> $200 \mathrm{pmol} / \mathrm{L}$ untreated) supported our hypothesis that he had both PTHrP and calcitriol-mediated hypercalcemia.

\section{Conclusions}

We present a rare case of combined PTHrP and calcitriol production by a metastatic anal cancer. Overall, the prognosis is poor in patients with CRC and PTHrP-induced hypercalcemia. Bisphosphonate and glucocorticoid therapy can be temporizing in PTHrP-induced and calcitriol-induced hypercalcemia, respectively, but effective anti-cancer therapy is essential to the management of hypercalcemia of malignancy.

\section{Disclosure}

The authors have nothing to disclose.

\section{Abbreviations}

PTH: parathyroid hormone; PTHrP: parathyroid hormone-related peptide; $25(\mathrm{OH}) \mathrm{D}: 25$-hydroxyvitamin $\mathrm{D} ; 1,25(\mathrm{OH})_{2} \mathrm{D}$ : 1,25-dihydroxyvitamin D or calcitriol; HHM: humoral hypercalcemia of malignancy; CRC: colorectal cancer

\section{References}

1. Fisken RA, Heath DA, Somers S, Bold AM. Hypercalcaemia in hospital patients. Clinical and diagnostic aspects. Lancet. 1981;1(8213):202-207.

2. Horwitz MJ, Hodak SP, Stewart AF. Non-Parathyroid Hypercalcemia. Primer on the metabolic bone diseases and disorders of mineral metabolism. John Wiley \& Sons, Inc., 2013: 562-571.

3. Stewart AF. Clinical practice. Hypercalcemia associated with cancer. N Engl J Med. 2005;352(4):373-379.

4. Burtis WJ, Brady TG, Orloff JJ, Ersbak JB, Warrell RP, Jr., Olson BR, Wu TL, et al. Immunochemical characterization of circulating parathyroid hormone-related protein in patients with humoral hypercalcemia of cancer. N Engl J Med. 1990;322(16):1106-1112.

5. Clines GA, Guise TA. Hypercalcaemia of malignancy and basic research on mechanisms responsible for osteolytic and osteoblastic metastasis to bone. Endocr Relat Cancer. 2005;12(3):549-583.

6. Roodman GD. Mechanisms of bone metastasis. N Engl $\mathrm{J}$ Med. 2004;350(16):1655-1664.

7. Donovan PJ, Sundac L, Pretorius CJ, d'Emden MC, McLeod DS. Calcitriol-mediated hypercalcemia: causes and course in 101 patients. J Clin Endocrinol Metab. 2013;98(10):4023-4029.

8. Nussbaum SR, Gaz RD, Arnold A. Hypercalcemia and ectopic secretion of parathyroid hormone by an ovarian carcinoma with rearrangement of the gene for parathyroid hormone. N Engl J Med. 1990;323(19):1324-1328.

9. Strewler GJ, Stern PH, Jacobs JW, Eveloff J, Klein RF, Leung SC, Rosenblatt M, et al. Parathyroid hormonelike protein from human renal carcinoma cells. Structural and functional homology with parathyroid hormone. J Clin Invest. 1987;80(6):1803-1807.

10. Asa SL, Henderson J, Goltzman D, Drucker DJ. Parathyroid hormone-like peptide in normal and neoplastic human endocrine tissues. J Clin Endocrinol Metab. 1990;71(5):1112-1118.

11. Berkelhammer $\mathrm{CH}$, Baker AL, Block GE, Bostwick DG, Michelassi F. Humoral hypercalcemia complicating aden- 
osquamous carcinoma of the proximal colon. Dig Dis Sci. 1989;34(1):142-147.

12. Chevinsky AH, Berelowitz M, Hoover HC, Jr. Adenosquamous carcinoma of the colon presenting with hypercalcemia. Cancer. 1987;60(5):1111-1116.

13. Cooper Worobey C, Magee CC. Humoral hypercalcemia of malignancy presenting after oncologic surgery. Kidney Int. 2006;70(1):225-229.

14. de Souza PL, Friedlander ML. Humoral hypercalcemia associated with adenocarcinoma of the rectum. A case report and review of the literature. Am J Clin Oncol. 1995;18(2):126-129.

15. Fujita T, Fukuda K, Nishi H, Takao T, Ohmura Y, Mano M, Komatsubara S. Paraneoplastic hypercalcemia with adenosquamous carcinoma of the colon. Int J Clin Oncol. 2005;10(2):144-147.

16. Gurney H, Grill V, Martin TJ. Parathyroid hormonerelated protein and response to pamidronate in tumourinduced hypercalcaemia. Lancet. 1993;341(8861):16111613.

17. Hernandez JM, Shibata D. Paraneoplastic hypercalcemia caused by an invasive squamous cell carcinoma arising from a giant anal condyloma acuminatum. Int J Colorectal Dis. 2009;24(3):359-360.

18. Kubota H, Koyama Y, Hojo K et al. Adenosquamous cell carcinoma of the colon with severe hypercalcemia: Report of two cases. Japanese Journal of Clinical Oncology. 1980;10:311-319.

19. Links M, Ho H, Clingan P, Diamond T. Hypercalcaemia in a patient with fatal adenosquamous carcinoma of the colon. Med J Aust. 1994;160(5):286-287.

20. Lortholary AH, Cadeau SD, Bertrand GM, Guerin-Meyer VI, Gamelin EC, Audran MJ. Humoral hypercalcemia in patients with colorectal carcinoma: report of two cases and review of the literature. Cancer. 1999;86(11):22172221.

21. Luh JY, Han ES, Simmons JR, Whitehead RP. Poorly differentiated colon carcinoma with neuroendocrine features presenting with hypercalcemia and cutaneous metastases: case report and review of the literature. Am J Clin Oncol. 2002;25(2):160-163.

22. March R, Ulin R, Puccio C, Savino J, Arlin Z, Ahmed T, Mittelman A. Hypercalcemia associated with adenocarcinoma of the rectum. A case report and review of the literature. Anticancer Res. 1991;11(6):2029-2030.

23. Moll UM, Ilardi CF, Zuna R, Phillips ME. A biologically active parathyroid hormone-like substance secreted by an adenosquamous carcinoma of the transverse colon. Hum Pathol. 1987;18(12):1287-1290.

24. Nobusawa S, Sato S, Matsumoto A, Yamada T, Tanaka N. Cloacogenic anal carcinoma presenting with humoral hypercalcemia: report of a case. Surg Today. 1995;25(11):970-973.

25. Omenn GS, Roth SI, Baker WH. Hyperparathyroidism associated with malignant tumors of nonparathyroid origin. Cancer. 1969;24(5):1004-1011.

26. Palvio DH, Sorensen FB, Klove-Mogensen M. Stem cell carcinoma of the colon and rectum. Report of two cases and review of the literature. Dis Colon Rectum.
1985;28(6):440-445.

27. Petrelli NJ, Valle AA, Weber TK, Rodriguez-Bigas M. Adenosquamous carcinoma of the colon and rectum. Dis Colon Rectum. 1996;39(11):1265-1268.

28. Sakata J, Wakai T, Shirai Y, Sakata E, Hasegawa G, Hatakeyama K. Humoral hypercalcemia complicating adenocarcinoma of the sigmoid colon: report of a case. Surg Today. 2005;35(8):692-695.

29. Sekine M, Takami H. Combination of calcitonin and pamidronate for emergency treatment of malignant hypercalcemia. Oncol Rep. 1998;5(1):197-199.

30. Sgourakis G, Lanitis S, Karaliotas C. Clinical challenges and images in GI. Anal tumor with refractory hypercalcemia. Gastroenterology. 2010;138(5):1667, 2025.

31. Sidler B, Alpert L, Henderson JE, Deckelbaum R, Amizuka N, Silva JE, Goltzman D, et al. Amplification of the parathyroid hormone-related peptide gene in a colonic carcinoma. J Clin Endocrinol Metab. 1996;81(8):28412847.

32. Teo M, Dhadda A, Gunn J. Paraneoplastic hypercalcaemia in squamous cell carcinoma of the anus: first reported case. Clin Oncol (R Coll Radiol). 2008;20(9):718.

33. Thompson JT, Paschold EH, Levine EA. Paraneoplastic hypercalcemia in a patient with adenosquamous cancer of the colon. Am Surg. 2001;67(6):585-588.

34. Wu F, Walls J, Howat J. Humoral hypercalcaemia of malignancy associated with squamous cell carcinoma of the anus. Colorectal Dis. 2011;13(9):e316-317.

35. Mallorry TB. Case records of the massachusetts general hospital- Case 27461. New England Journal of Medicine. 1941;225:789-791.

36. Mozaffarian G. Hypercalcemia associated with malignancies unexplained by bone metastasis. Case reports and review of literature. J Maine Med Assoc. 1969;60(9):205207.

37. Benit A, Allard J, Rimailho J, Fauvel J, Escourrou G, Vezzosi D, Donadille F, et al. Persistent and moderate hypercalcemia related to an ovarian clear cell adenocarcinoma: Pre- and postoperative parathyroid hormone related-peptide and 1,25-dihydroxyvitamin D3 levels. J Endocrinol Invest. 2006;29(5):443-449.

38. Fuminori Taniguchi JK, Riko Kitazawa and Naoki Terakawa. Successful management of humoral hypercalcemia of malignancy in a patient with ovarian cancer. Yonago Acta medica. 2000;43:81-86.

39. Hoekman K, Tjandra YI, Papapoulos SE. The role of 1,25-dihydroxyvitamin $\mathrm{D}$ in the maintenance of hypercalcemia in a patient with an ovarian carcinoma producing parathyroid hormone-related protein. Cancer. 1991;68(3):642-647.

40. Shivnani SB, Shelton JM, Richardson JA, Maalouf NM. Hypercalcemia of malignancy with simultaneous elevation in serum parathyroid hormone--related peptide and 1,25-dihydroxyvitamin $\mathrm{D}$ in a patient with metastatic renal cell carcinoma. Endocr Pract. 2009;15(3):234-239.

41. Van den Eynden GG, Neyret A, Fumey G, Rizk-Rabin M, Vermeulen PB, Bouizar Z, Body JJ, et al. PTHrP, calcitonin and calcitriol in a case of severe, protracted and refractory hypercalcemia due to a pancreatic neuroendo- 
crine tumor. Bone. 2007;40(4):1166-1171.

42. Wysolmerski JJ. Parathyroid hormone-related protein. primer on the metabolic bone diseases and disorders of mineral metabolism. John Wiley \& Sons, Inc., 2013: 215223.

43. Nakayama K, Fukumoto S, Takeda S, Takeuchi Y, Ishikawa T, Miura M, Hata K, et al. Differences in bone and vitamin $\mathrm{D}$ metabolism between primary hyperparathyroidism and malignancy-associated hypercalcemia. J Clin Endocrinol Metab. 1996;81(2):607-611.

44. Stewart AF, Vignery A, Silverglate A, Ravin ND, LiVolsi V, Broadus AE, Baron R. Quantitative bone histomorphometry in humoral hypercalcemia of malignancy: uncoupling of bone cell activity. J Clin Endocrinol Metab. 1982;55(2):219-227.

45. Horwitz MJ, Tedesco MB, Sereika SM, Hollis BW, Garcia-Ocana A, Stewart AF. Direct comparison of sustained infusion of human parathyroid hormone-related protein-(1-36) [hPTHrP-(1-36)] versus hPTH-(1-34) on serum calcium, plasma 1,25-dihydroxyvitamin $\mathrm{D}$ concentrations, and fractional calcium excretion in healthy human volunteers. J Clin Endocrinol Metab. 2003;88(4):16031609.

46. Major P, Lortholary A, Hon J, Abdi E, Mills G, Menssen $\mathrm{HD}$, Yunus F, et al. Zoledronic acid is superior to pamidronate in the treatment of hypercalcemia of malignancy: a pooled analysis of two randomized, controlled clinical trials. J Clin Oncol. 2001;19(2):558-567.

47. Major P. The use of zoledronic acid, a novel, highly potent bisphosphonate, for the treatment of hypercalcemia of malignancy. Oncologist. 2002;7(6):481-491.

48. Hu MI, Glezerman IG, Leboulleux S, Insogna K, Gucalp R, Misiorowski W, Yu B, et al. Denosumab for treatment of hypercalcemia of malignancy. J Clin Endocrinol Metab. 2014;99(9):3144-3152.

49. Churilla TM, Brereton HD, Klem M, Peters CA. Vitamin $\mathrm{D}$ deficiency is widespread in cancer patients and correlates with advanced stage disease: a community oncology experience. Nutr Cancer. 2012;64(4):521-525.

50. Breen TL, Shane E. Prolonged hypocalcemia after treatment with zoledronic acid in a patient with prostate cancer and vitamin D deficiency. J Clin Oncol. 2004;22(8):15311532.

51. Smith SJ, Rucka AK, Berry JL, Davies M, Mylchreest $\mathrm{S}$, Paterson CR, Heath DA, et al. Novel mutations in the 1alpha-hydroxylase (P450c1) gene in three families with pseudovitamin D-deficiency rickets resulting in loss of functional enzyme activity in blood-derived macrophages. J Bone Miner Res. 1999;14(5):730-739.

52. Adams JS, Hewison M. Extrarenal expression of the 25-hydroxyvitamin D-1-hydroxylase. Arch Biochem Bi- ophys. 2012;523(1):95-102.

53. Seymour JF, Gagel RF, Hagemeister FB, Dimopoulos MA, Cabanillas F. Calcitriol production in hypercalcemic and normocalcemic patients with non-Hodgkin lymphoma. Ann Intern Med. 1994;121(9):633-640.

54. Seymour JF, Gagel RF. Calcitriol: the major humoral mediator of hypercalcemia in Hodgkin's disease and nonHodgkin's lymphomas. Blood. 1993;82(5):1383-1394.

55. Kallas M, Green F, Hewison M, White C, Kline G. Rare causes of calcitriol-mediated hypercalcemia: a case report and literature review. J Clin Endocrinol Metab. 2010;95(7):3111-3117.

56. Tangpricha V, Flanagan JN, Whitlatch LW, Tseng CC, Chen TC, Holt PR, Lipkin MS, et al. 25-hydroxyvitamin D-1alpha-hydroxylase in normal and malignant colon tissue. Lancet. 2001;357(9269):1673-1674.

57. Quarles LD. Role of FGF23 in vitamin D and phosphate metabolism: implications in chronic kidney disease. Exp Cell Res. 2012;318(9):1040-1048.

58. Reichel H, Koeffler HP, Barbers R, Norman AW. Regulation of 1,25-dihydroxyvitamin D3 production by cultured alveolar macrophages from normal human donors and from patients with pulmonary sarcoidosis. J Clin Endocrinol Metab. 1987;65(6):1201-1209.

59. Conron M, Young C, Beynon HL. Calcium metabolism in sarcoidosis and its clinical implications. Rheumatology (Oxford). 2000;39(7):707-713.

60. Adams JS, Gacad MA. Characterization of 1 alpha-hydroxylation of vitamin D3 sterols by cultured alveolar macrophages from patients with sarcoidosis. J Exp Med. 1985;161(4):755-765.

61. Sandler LM, Winearls CG, Fraher LJ, Clemens TL, Smith $\mathrm{R}, \mathrm{O}$ 'Riordan JL. Studies of the hypercalcaemia of sarcoidosis: effect of steroids and exogenous vitamin D3 on the circulating concentrations of 1,25-dihydroxy vitamin D3. Q J Med. 1984;53(210):165-180.

62. Schilling T, Pecherstorfer M, Blind E, Leidig G, Ziegler R, Raue F. Parathyroid hormone-related protein (PTHrP) does not regulate 1,25-dihydroxyvitamin D serum levels in hypercalcemia of malignancy. J Clin Endocrinol Metab. 1993;76(3):801-803.

63. Horwitz MJ, Tedesco MB, Sereika SM, Syed MA, Garcia-Ocana A, Bisello A, Hollis BW, et al. Continuous PTH and PTHrP infusion causes suppression of bone formation and discordant effects on 1,25(OH)2 vitamin D. J Bone Miner Res. 2005;20(10):1792-1803.

64. Horwitz MJ, Tedesco MB, Sereika SM, Prebehala L, Gundberg CM, Hollis BW, Bisello A, et al. A 7-day continuous infusion of PTH or PTHrP suppresses bone formation and uncouples bone turnover. J Bone Miner Res. 2011;26(9):2287-2297. 